\title{
IMPACTS OF AEROBIC EXERCISE ON HDL LEVEL OF ADULTS; IT'S SOCIAL IMPLICATIONS IN EDUCATIONAL INSTITUTES
}

\author{
Noor Muhammad Marwat ${ }^{*}$, Shah Khalid ${ }^{2}$, Pir Muhammad Abdul Aziz Shah ${ }^{3}$, Fayaz ul Hasnain ${ }^{4}$, Rashid Naeem \\ Khan $^{5}$ \\ ${ }^{1 *}$ Lecturer, Department of Sports Sciences and Physical Education, Gomal University D.I Khan, Pakistan; ${ }^{2} \mathrm{PhD}$ Scholar, \\ University of Lahore, Pakistan; ${ }^{3} \mathrm{PhD}$ Scholar, University of Sindh, Jamshoro, Pakistan; ${ }^{4}$ M.Phil Scholar, IER Gomal \\ University D.I.Khan, Pakistan; ${ }^{5}$ Lecturer Department of Sports Sciences University of Sargodha, Pakistan. \\ Email: ${ }^{1 *}$ marwatnoor@yahoo.com, ${ }^{2}$ shahkhalid222@ gmail.com, ${ }^{3}$ peershah4880@ gmail.com, \\ ${ }^{4}$ malikfayyaz367@gmail.com, ${ }^{5}$ rashid_nkhan@yahoo.com
}

Article History: Received on $29^{\text {th }}$ June 2021, Revised on $16^{\text {th }}$ July 2021, Published on $19^{\text {th }}$ July 2021

\begin{abstract}
Purpose: The purpose of this study to find out the impacts of a 6-weeks supervised aerobic exercise protocol on HighDensity Lipoprotein among adults aged between 25-35 years was evaluated.

Methodology: Researchers through a non-probability sampling procedure selected thirty (30) volunteers ranging from 25-35 untrained adults from Lakki Marwat. Researchers used a six-week aerobic exercise protocol to collect relevant information from the targeted dependent variables. The CHOD PAP method was used to measure the High-Density Lipoprotein (HDL) of adults. All the data collected from pre-and post- (HDL) tests were recorded in numerical form and analyzed by using a t-test.
\end{abstract}

Main Findings: The results of the study indicate that the six-week aerobic exercise protocol program had no significant difference on pre-and post-intervention quantities of HDL of Experimental Group which is (P>0.05).

The implication of the Study: The aerobic exercise programs used for this particular study may help adults to improve and maintain their health status, proper social stature, and lipid profile. An increase in the HLD is ideal as this increase in the HDL helps to prevent cardiovascular diseases particularly the heart valves from stroke and cardiac arrest and academic achievements of the participants.

Novelty: So far, no particular research has been conducted on the social implications of exercise effects on adults. Future researchers may work on the social habits of physically fit adults and their input to society.

Keywords: Aerobic Exercise, Protocol, HDL Level, Adults, Social Implications, Educational Institutes.

\section{INTRODUCTION}

Coronary heart diseases (CHD) are considered the main cause of heart attacks and cardiac arrest. A worldwide survey was conducted in 2019 as reported in "Journal of American College of Cardiology" published in December 2020. In the results, it has been reported that heart diseases deaths are mainly due to the narrowing of arteries (Ischemic). The people with ages of 30-70 years are mostly affected. More than 9.6 million males and 8.9 million females are a victim of CHD, of whom 6 million falls within the range of 30-70 yeas age group of people and their social aspect of life is badly affected. In another study, it was found that in the last 20 years 34.4 million people were affected by heart-related disabilities in Pakistan. There are $41 \%$ hypertension patients, $17.3 \%$ high cholesterol, and $2.8 \%$ of stroke among those people. It has been reported that Pakistani adults pay less attention to the risk of CVD (World Health Organization CVD, 2018). Hypertension and dyslipidemia have been declared the most important risk factors. In adults with raised BMI, a rise in blood pressure and a higher level of cholesterol in adults has been observed. This was reported in," Current Trends of Cardio Vascular Risk Determinants in Pakistan, PMC, October 2018. It was also shown in the results that low level of LDL, low level of HDL, lipoprotein cholesterol and increased lipid level was also prominent in adults avoiding exercises. BMI has significant positive effects on cardiovascular diseases. In urban Asian Indians, exercise has paramount effects in decreasing CVD. In Pakistan, the vulnerability towards CVD in adults is alarmingly increasing (Reis JP et al, 2013). According to the results of another study on the Chines population, it was reported that exercise had positive effects on LDL, CVD, and BMI (De Waard MC et al, 2009). The CVD are well controlled by taking regular exercises by adults (Aziz K, Faruqui, et al, 2012). The pace of increase of CVD can easily be retained among the adults of Canada; such findings have been shown in an investigation (Thibault V Belanger, et al, 2016). The CHD risks did not differ as shown in the results of a study by age group. This study was conducted on Pakistani adults (Barolia R Sayani $\mathrm{AH}, 2017)$. The absence of exercise/training in adults is the main cause of CHD in the sample chosen for study in England (Kyle, RG, Wills, J, et al, 2017). In the young population, the CHD rate and risks are higher as reported by the results of a research study (Gupta R Misra A, et al, 2009). The recommendations of a study conducted on North East London adults have revealed that focus on exercising habits will lessen hypertension, keep away from diabetes, and dyslipidemia (Coronary Heart Diseases Statistics, 2001). In the present research, the causes and prevention of coronary heart diseases were tried to point out in the adults of Lakki Marwat. The literature and results of the study depict that sedentary life in adults is the main cause of CHD. It has also been established that a higher intake of saturated fat from red meat also develops the risk of various heart diseases (WHO, NCD Profiles, 2015). It is pertinent to mention here that the results and reviewed literature has made it clear enough that regular habits of training have paramount importance in 
adult lives. In Pakistan, mainly very few attempts have been made to search out the leading causes behind the increased ratio of CHD. The experts in the field of sport and medical sciences are requested to work on this vital aspect and make the future of the country aware of the dangers of hypertension, increased lipid levels, higher cholesterol levels, more heart problems and boost up the learning capabilities of adults. The leading cause behind the experimental study of the researcher was to evaluate properly the impacts of aerobic exercise protocol on the HDL level of adults and their social aspect of academic learning. The area selected for the study was District Lakki Marwat of KP, Pakistan.

\section{Objectives of the Study}

1. To check the comparison of Pre- and Post-test effects of exercise protocol on HDL of Control Group in adults and its effects on academic achievements of adults.

2. To assess the comparison of Pre- and Post-test results of exercise protocol on HDL of an Experimental Group of adults affecting the social aspect of participants.

\section{LITERATURE REVIEW}

\section{Hypotheses}

Ho1: There is no significant difference between the pre-and post-intervention measurements of HDL of Control Group (CG) on the sociability of adults.

Ho2: There is no significant difference between the pre-and post-intervention measurements of HDL of Experimental Group (EG) on academic achievements of participants.

\section{RESEARCH METHOD}

Researchers used a single-dimensional design with two groups assigning different training batteries. For the study Thirty (30) untrained adults from Lakki Marwat were selected with a range of age between 25-35 years. The chosen sample was split down into two equal groups each of (15) adults namely, (group A) Experimental Group (EG) and Group B (Control Group). A pre-test was applied to the subjects before administering the aerobic exercise protocol. The other group of experimental group has to be involved in the prescribed aerobic exercise protocol for six weeks under the strict supervision of the researcher, whereas the subjects of the control group were offered no treatment. After six weeks, the post-test was applied to the experimental group.

\section{Participants}

This particular study was aimed to examine the effects of aerobic exercise protocol upon HDL level of adults aging 2535 years and its effects on the social aspects of the student adults. The researchers selected Thirty (30) volunteer untrained adult students from District Lakki Marwat.

\section{Instrument}

The study in hand was conducted to assess the effects of aerobic exercise protocol upon cholesterol level of adults with the age group of 25-35 years and assess its social impacts on adult students. After going through the available kinds of literature and the expert opinion of training/conditioning experts, the proposed six 6-weeks aerobic exercise protocol was decided upon to collect relevant data from selected dependent variables.

\section{Reliability}

The High-Density Lipoprotein (HDL) of the sample of adult students were measured through the CHOD PAP method. The Blood samples of the volunteers were taken and poured into the test lines. Blood samples of the adults were centrifuged in a centrifuge machine for 10 minutes maximum to take the serum. Later on, the serum was converted to test lines of one $\mathrm{ml}$, and then incubated at $37 \mathrm{oC}$. The absorbance of the volunteer adults 6-month was measured for one hour against the reagent blank.

\section{Data Analysis}

The collected data were tabulated and analyzed by using statistical tests i-e independent sample t-Test and Paired Sample $\mathrm{t}$-Test in SPSS version 24.00. The researcher used an independent sample t-Test to compare the anthropometric measurements of two different groups; Control Group (CG) and Experimental Group (EG). It was statistically determined that whether there was statistical evidence that the means of the two groups are significantly different in terms of height, weight and BMI, and social effects on their lives. The researcher applied Paired Sample t-Test to determine the comparison of Pre- and Post-test results of exercise protocol on lipid profile of CG and EG in adults respectively.

\section{RESULTS}

Anthropometric Parameters 
Table 1: Pre-intervention anthropometric parameters in young adults of the control and experimental groups ( $\mathrm{n}=30$ )

\begin{tabular}{lccc}
\hline Parameters & (CG) Mean \pm SD & (EG) Mean \pm SD & P-Value \\
\hline Age & $31.23 \pm 1.72$ & $32.76 \pm 1.43$ & 0.129 \\
\hline Height $($ Inches) & $60.92 \pm 1.63$ & $64.61 \pm 2.36$ & 0.539 \\
\hline Weight $(\mathrm{kg})$ & $74.97 \pm 4.60$ & $74.06 \pm 5.92$ & 0.497 \\
\hline Body Mass Index $(\mathrm{kg} / \mathrm{m}) 2$ & $27.99 \pm 2.29$ & $28.02 \pm 2.23$ & 0.491 \\
\hline
\end{tabular}

Significant at 0.05 .

According to the analyzed data, the mean age, height, and weight of the control group were measured $31.23 \pm 1.72$, $60.92 \pm 1.63$, and $74.97 \pm 4.60$ respectively. Likewise, the data shows $32.76 \pm 1.43,64.61 \pm 2.36$, and $74.06 \pm 5.92$ respectively for the age, height, and weight of the experimental group. Similarly, the body mass index of both the control and experimental groups were recorded in $(\mathrm{kg} / \mathrm{m})$ for which the mean values were recorded as $28.23 \pm 2.39$ and $28.974 \pm$ 2.29. T-test was applied to examine the differences in anthropometric parameters of adults for both the experimental and control groups and the results indicated that there was no statistically significant difference in the Pre-intervention anthropometric parameters in adults in the experimental and control groups applying 6-week aerobic exercise protocol as well as on the academic achievements of the participants.

\section{Effects of Aerobic Exercises on High-density Lipoprotein (HDL)}

Table 2: Comparison of Pre and Post-test results regarding HDL of Control Group $(n=15)$

\begin{tabular}{lccccc}
\hline Control Group & $\mathbf{N}$ & Mean & Std. Dev & t-Value & P-Value \\
\hline Pre-test & 15 & 44.679 & 5.907 & .046 & .947 \\
\hline Post-test & 15 & 45.453 & 3.989 & & \\
\hline
\end{tabular}

Significant at 0.05 .

The above table results show the Pre- and Post-intervention measurements of HDL of the Control Group. After a 6-week aerobic exercise protocol, the volunteer adults of CG exhibited no significant difference in HDL and sociability of adult students being $(\mathrm{P}>0.05)$.

Table 3: Comparison of Pre and Post-test results regarding HDL of Experimental Group ( $\mathrm{n}=15)$

\begin{tabular}{llllll}
\hline Control Group & $\mathrm{N}$ & Mean & Std. Dev & t-Value & P-Value \\
\hline Pre-test & 15 & 46.439 & 6.012 & -.3725 & .701 \\
\hline Post-test & 15 & 47.396 & 5.946 & & \\
\hline
\end{tabular}

Significant at 0.05 .

Table No: 3 Shows the Pre- and Post-intervention quantities of HDL of the Experimental Group of tested adults. The results of analyzed data show that $\mathrm{P}=0.701$, which is higher than the standard value of $\mathrm{p}$ i.e., 0.05 . It was found that after the application of the 6-week aerobic exercise protocol, no significant difference was observed between pre-and postintervention quantities of HDL of Experimental Group and academic social environment of subjects being $(\mathrm{P}>0.05)$.

\section{DISCUSSION}

In this varied study, the researcher has tried to evaluate the impacts of a 6-weeks aerobic exercise protocol upon HDL levels of student adults with age between 25-35 years and its effects on their academics, belonging to Lakki Marwat Khyber Pakhtunkhwa, Pakistan. After the application of the 6-week aerobic exercise protocol, the adults of CG exhibited no significant difference in HDL ( $\mathrm{P}>0.05)$. The proposed hypothesis of the study concentrated on the impacts of aerobic exercise protocol on the high-density lipoprotein (HDLP) of adults and social habits. It has been confirmed from the findings of the study that after the aerobic exercise protocol, no significant difference was exhibited between Pre- and Post-intervention quantities of HDL of the adults of the Experimental Group i.e., $(\mathrm{P}>0.05)$. It is concluded that aerobic exercise helped in increasing HDL of Experimental Group volunteer adults with reasonable change in their social behavior. The findings of other relevant studies have shown that although exercise may not produce any quantitative results in reducing the total cholesterol and low-density lipoprotein (LDL) levels, it can help in bringing change in LDL subtraction, increase in concentrating large LDL, and reduces in small LDL. The increase in HLD is considered good because the increase in HDL helps in preventing the heart valves from stroke and cardiac arrest. These findings are in line with the statement that HDL is considered as one of the major mediators that, helps in the reverse transportation of cholesterol from arterial walls to the liver of the body. The findings of the study affirm that the hypothetical assumption that, rise in HDL levels of adults contributes to the reduction of cardiovascular risks.

\section{CONCLUSION}

The researcher concluded in light of the findings of the present study that aerobic exercises have a positive impact on HDL of adults having age 25-35 years and their social approach during academic activities. The HDL of adults who participated in the 6-week aerobic exercise protocol was increased and positive change in their behaviors was observed. 
This increase of HLD is ideal and considered best as it helps in preventing the heart valves from stroke, blockage, and heart attack. The researcher recommends a regular aerobic exercise program for the adult to minimize the probability of various cardiovascular diseases their complications and strengthen the social aspect of the student adults.

\section{LIMITATIONS}

The researchers having in mind the financial constraints and Covid-19 prevailing situations restricted the study only to the adults of Lakki Marwat, KP, Pakistan.

\section{AUTHORS CONTRIBUTION}

Noor Muhammad Marwat ${ }^{1}$, Shah Khalid ${ }^{2}$, Pir Muhammad Abdul Aziz Shah ${ }^{3}$, Fayaz ul Hasnain ${ }^{4}$, Rashid Naeem Khan ${ }^{5}$ : 1 - Study design; 2 - Data collection; 3- Statistical analysis; 4 - Manuscript preparation; 5- Funds collection.

\section{REFERENCES}

1. Alm, J., Bloomquist, K. M., McKee, M. (2015). On the external validity of laboratory tax compliance experiments. Economic Inquiry, 53, 1170-1186. https://doi.org/10.1111/ecin.12196

2. Aziz, K., Faruqui, A.(2012). Awareness of cardiovascular disease including life styles in a lower middle class urban community in an Asian country, Pak Heart, 41, 1-10.

3. Bacharach, M. (2006). Interactive team reasoning: A contribution to the theory of co-operation. Research in Economics, 53, 117-147. https://doi.org/10.1006/reec.1999.0188

4. Barolia, R., Sayani, A.H.(2017). Risk factor of cardiovascular disease and its recommendations in Pakistan context. Journal of the Pakistan Medical Association, 67, 1723-1729.

5. Bastian, B., Jetten, J., Ferris, L. J. (2014). Pain as social glue: Shared pain increases cooperation. Psychological Science, 25, 2079-2085. https://doi.org/10.1177/0956797614545886

6. Davis, A., Taylor, J., Cohen, E. (2015). Social bonds and exercise: Evidence for a reciprocal relationship. PLoS One, 10, e0136705.10.1371. https://doi.org/10.1371/journal.pone.0136705

7. de Waard, M.C., Duncker, D.J. (2009). Prior exercise improves survival, infarct healing, and left ventricular function after myocardial infarction. J Appl Physiol, 107(3), 928-36. https://doi.org/10.1152/japplphysiol.91 $\underline{281.2008}$

8. Di Bartolomeo, G., Dufwenberg, M., Papa, S., Passarelli, F. (2017). Promises, expectations, and causation. Mimeo, Sapienza University of Rome. https://doi.org/10.2139/ssrn.3202143

9. Felfe, C., Lechner, M., Steinmayr, A. (2016). Sports and child development. PLoS One, 11 , e0151729. https://doi.org/10.1371/journal.pone.0151729

10. Framework for health information systems and core indicators for monitoring health situation and health system performance 2015. Cairo; WHO Regional Office for the Eastern Mediterranean, 2015.

11. Gupta, R., Misra, A., Vikram, N.K., Kondal, D., Gupta, S.S., Agrawal, A., Pandey. R.M. (2009). Younger age of escalation of cardiovascular risk factors in Asian Indian subjects. BMC Cardiovasc Disord, 9, 28. https://doi.org/10.1186/1471-2261-9-28

12. Hoye, R., Nicholson, M., Brown, K. (2015). Involvement in sport and social connectedness. International Review for the Sociology of Sport, 50, 3-21. https://doi.org/10.1177/1012690212466076

13. Klimecki, O. M., Mayer, S. V., Jusyte, A., Scheeff, J., Schönenberg, M. (2016). Empathy promotes altruistic behavior in economic interactions. Nature Scientific Reports, 6, 31961. https://doi.org/10.1038/srep31961

14. Kyle, R.G., Wills, J., Mahoney, C., Hoyle, L., Kelly, M., Atherton, I.M. (2017). Obesity prevalence among healthcare professionals in England: a cross-sectional study using the Health Survey for England. BMJ Open, 7 , e018498. https://doi.org/10.1136/bmjopen-2017-018498

15. MacDonald, D. J., Côté, J., Eys, M., Deakin, J. (2011). The role of enjoyment and motivational climate in relation to the personal development of team sport athletes. The Sport Psychologist, 25, 32-46. https://doi.org/10.1123/tsp.25.1.32

16. Pawlowski, T., Schuttoff, U., Downward, P., Lechner, M. (2016). Can sport really help to meet the millennium development goals? Evidence from children in Peru. Journal of Sports Economics, 19(4), 498-521. https://doi.org/10.1177/1527002516661601

17. Reis, J.P., Loria, C.M., Lewis, C.E., Powell-Wiley, T.M., Wei, G.S., Carr, J.J. et al. (2013). Association between duration of overall and abdominal obesity beginning in young adulthood and coronary artery calcification in middle age. JAMA, 310(3), 280-288. https://doi.org/10.1001/jama.2013.7833

18. Thibault, V., Bélanger, M., LeBlanc, E. et al.(2016). Factors that could explain the increasing prevalence of type 2 diabetes among adults in a Canadian province: a critical review and analysis. Diabetol Metab Syndr, 8, 71. https://doi.org/10.1186/s13098-016-0186-9

19. World Health Organization CVD, 2018. 